Michael Quinlan ${ }^{1}$

Richard Johnstone ${ }^{2}$

Phillip James ${ }^{3}$

Igor Nossar ${ }^{4}$

\section{Regulamentação das cadeias de fornecedores para proteger a saúde e segurança de trabalhadores vul- neráveis}

\author{
Supply chain regulation to protect the occupational health and \\ safety of vulnerable workers
}

\footnotetext{
${ }^{1}$ School of Organisation and Management, University of New South Wales, Sydney, Australia.

${ }^{2}$ Law School, Griffith University, Nathan, Queensland, Australia.

${ }^{3}$ Business School, Middlesex University, London, UK.

${ }^{4}$ Textile, Clothing and Footwear Union, Campsie, Australia.
}

\begin{abstract}
Resumo
Um grande número de pesquisas recentes evidencia que as estratégias de subcontratação de serviços e produtos e a contratação de trabalhadores contingentes, nas chamadas cadeias de fornecedores, afetam os processos de planejamento e tomada de decisão de maneira a solapar seriamente a Segurança e Saúde dos Trabalhadores (SST). Complexas cadeias de fornecedores apresentam um desafio para a ação de regulamentação, pois a responsabilidade legal pela SST está difusa dentre um maior espectro de atores sociais, com mais dificuldades para focalizar os principais tomadores de decisão, e as agências de governo encontram maiores dificuldades logísticas na tentativa de proteger legalmente os trabalhadores contingentes, como os temporários e terceirizados. Em certo número de indústrias, esses problemas têm instigado novas formas de intervenção regulamentadora, incluindo mecanismos para alocar a responsabilidade legal no topo das cadeias de fornecedores, dispositivos de acompanhamento contratual e crescente envolvimento da indústria, dos sindicatos e da comunidade na fiscalização do cumprimento da lei. Depois de descrever os problemas acima referidos, este artigo examina recentes esforços para regulamentar as cadeias de fornecedores para salvaguardar a SST no Reino Unido e na Austrália.
\end{abstract}

Palavras-chaves: cadeias de fornecedores, terceirização, saúde e segurança dos trabalhadores, regulamentação, ergonomia.

\begin{abstract}
The last two decades have witnessed a fragmentation of previously integrated systems of production and service delivery with the advent of boundary-less, networked and porous organisational forms. This trend has been associated with the growth of outsourcing and increased use of contingent workers. One consequence of these changes is the development of production/service delivery systems based on complex national and international networks of multi-tiered subcontracting increasingly labelled as supply chains. A growing body of research indicates that subcontracting and contingent work arrangements affect design and decision-making processes in ways that can seriously undermine occupational health and safety (OHS). Elaborate supply chains also present a regulatory challenge because legal responsibility for OHS is diffused amongst a wider array of parties, targeting key decision-makers is more difficult, and government agencies encounter greater logistical difficulties trying to safeguard contingent workers. In a number of industries these problems have prompted new forms of regulatory intervention, including mechanisms for sheeting legal responsibility to the top of supply chains, contractual tracking devices and increasing industry, union and community involvement in enforcement. After describing the problems just alluded to this paper examines recent efforts to regulate supply chains to safeguard OHS in the United Kingdom and Australia.
\end{abstract}

Keywords: supply chains, subcontracting, health and safety, regulation, ergonomics. 
${ }^{5}$ Ou das "terceirizações".

\footnotetext{
${ }^{6}$ Optou-se em usar a expressão "trabalho contingente", originada nos Estados Unidos e muito utilizada na América do Norte, mas contendo também o significado de "emprego precário", originado na França e utilizado na Europa. O termo "precário" associa-se à insegurança no trabalho e não pressupõe permanência, continuidade ou estabilidade no emprego; o termo "contingente" refere-se a formas variadas de emprego por períodos de tempo específicos, quando necessários. (LOUIE et al., 2006).
}

\section{Introdução}

Cadeias de fornecedores referem-se a múltiplas camadas verticais de relacionamentos ou de redes envolvidas no fornecimento de produtos ou serviços. Freqüentemente implícita no uso do termo, está a noção de que essa complexa rede de relacionamentos é articulada ou está sendo gerenciada usualmente por e para benefício de um ator-chave dessa cadeia (como um grande varejista que obtém produtos agrícolas de qualidade a baixo custo) (CHRISTOPHER, 2005). Cadeias de fornecedores contêm a reação organizacional para as demandas logísticas complexas ou outras (por exemplo, as de qualidade ou custo), emergentes da fragmentação associada

\section{Os problemas da SST ligados à cadeia de fornecedores}

Com algumas exceções, existe pouca pesquisa sobre os efeitos à SST provocados por cadeias de fornecedores (WRIGHT \& LUND, 1998). No entanto, um grande número de pesquisas internacionais recentes evidencia que esses padrões complexos de subcontratação e o aumento no uso de trabalhadores contingentes - ambos elementos-chave em muitas cadeias de fornecedores - afetam os processos de planejamento e o processo de tomada de decisão dentro dos sistemas de produção e de prestação de serviços contratados de maneira a poder causar graves efeitos adversos à SST (QUINLAN et al., 2001a). Por exemplo, o curto ciclo e a volatilidade das relações de trabalho contingente podem minar os procedimentos de treinamento e de admissão, as regras informais de segurança e a comunicação entre trabalhadores. A terceirização freqüentemente envolve a transferência de atividades para pequenas empresas com recursos menores para gerir a SST. Estão associadas à intensificação do trabalho (às vezes ignorando considerações ergonômicas em termos de carga, limites de exposição e interfaces homem/máquina), às mudanças sutis em tarefas prescritas (por exemplo, desconsiderando procedimentos de segurança ou o uso de sistemas de proteção e eliminando rotinas de manutenção), à utilização de equipamentos em estado de uso não-ótimo e à fragmentação de toda a supervisão em SST.

Outras evidências fragmentadas sugerem que a articulação estreita entre os sistemas de produção e de entrega de serviços com a subcontratação de fornecedores ou contratação de serviços ou produtos de locais remotos ou diversos (incluindo de outros países). Desse modo, não é por acaso que o crescente discurso sobre as cadeias de fornecedores e sua administração tem coincidido com o crescimento das subcontratações $^{5}$ e/ou o deslocamento da produção (e uma correspondente redução de emprego em grandes companhias e o crescimento deste em pequenas e médias empresas) e o crescente uso de trabalhadores contingentes ${ }^{6}$ (incluindo trabalhadores autônomos e temporários ou contratados por curta duração).

nas cadeias de fornecedores não é freqüentemente acompanhada por qualquer articulação paralela da gestão da SST e da obediência às leis e regulamentações. De fato, algumas cadeias de fornecedores parecem ter sido preconizadas, ao menos em parte, devido às vantagens econômicas de se evitar as obrigações relativas à regulamentação em SST. A qualidade do produto e seu custo são controlados por rigorosos instrumentos de verificação, mas os resultados quanto à SST não o são, ao menos na base da cadeia. Grandes empresas manufatureiras e de comércio de países desenvolvidos têm cada vez mais realocado sua produção para países em desenvolvimento (geralmente via firmas subsidiárias ou satélites e subcontratadas) que possuem regulamentações de SST e de trabalho menos rigorosas (e fracamente fiscalizadas) (QUINLAN et al., 2001b). Mesmo aquelas atividades de produção e serviços que não são transferidas ao estrangeiro devido ao seu ciclo de tempo ou a outras considerações (como o efeito da moda na indústria do vestuário) podem ser afetadas. Considerações ergonômicas no projeto do local de trabalho podem ser negligenciadas ou enfraquecidas quando as atividades de produção são transferidas das grandes fábricas para as pequenas empresas ou de "fundo de quintal" e para os domicílios de trabalhadores. Deste modo, há evidência de que o deslocamento da fabricação de vestuário e atividades similares para os domicílios implica freqüentemente no uso de equipamentos inferiores ou em pior 
estado de conservação, planejamento deficiente do posto de trabalho, treinamento inadequado, pagamento inadequado que encoraja a realização de excessivas horas de trabalho, o mau planejamento temporal na programação das tarefas e o uso de trabalhadores menores de idade, até mesmo em países desenvolvidos, como a Austrália (MAYHEW \& QUINLAN, 1999). O predomínio de imigrantes recém-chegados na produção de roupas tem exacerbado os problemas, pois eles têm conhecimento limitado de seus direitos e são vulneráveis às explorações de intermediários (MAYHEW \& QUINLAN, 1999).

No transporte rodoviário, a competição entre transportadoras (já significante devido ao freqüente e grande número de pequenas empresas e de motoristas autônomos) tem sido intensificada por políticas governamentais de competição e de desregulamentação (como nos Estados Unidos, a liberalização do transporte rodoviário de cargas) e por práticas de gestão das cadeias de fornecedores pelos clientes, especialmente os grandes e influentes expedidores (como cadeias de varejo e afins) (PLEHWE, 2003; BELZER, 2000). O valor

\section{Desafios para a regulamentação}

Complexas cadeias de fornecedores podem apresentar um desafio particular para as agências de regulamentação encarregadas de salvaguardar a saúde e segurança dos trabalhadores.

De um lado, a legislação para SST em países como Austrália, Inglaterra e Canadá parece ser bem apropriada para abordar complexas cadeias de fornecedores. Os dispositivos gerais contidos nessas leis estabelecem obrigações não simplesmente para empregadores e trabalhadores, mas também para o amplo espectro de outros atores cujas ações podem afetar a SST. Isso inclui projetistas, fabricantes, fornecedores e importadores de equipamentos usados nos processos de trabalho, assim como os ocupantes dos locais de trabalho. As exigências legais presumem que há múltiplos responsáveis em dada situação de trabalho (com potencial para múltiplos processos judiciais nos casos de violação da lei).

O grau de responsabilidade e de obrigação legal é proporcional ao grau de controle exercido por cada parte envolvida (desse modo, as obrigações são mais onerosas para o empregador e o principal contratante do do frete tem sido comprimido ao mesmo tempo em que as mais severas exigências têm sido impostas com relação à programação de entrega (via uso do Just in Time). Respostas para essa pressão têm incluído pagamentos reduzidos e mais pagamentos para motoristas em situação precária (por exemplo, pagamento por viagem realizada e uso de motoristas com salários mais baixos provenientes do leste europeu), jornadas de trabalho mais longas (especialmente quando não são pagas as horas de espera nos depósitos etc.) e transferências dos valores de frete mais baixos das mais importantes transportadoras para pequenas firmas e motoristas autônomos por meio das, cada vez mais complexas, camadas de subcontratações (MAYHEW \& QUINLAN, 2006). Grande número de evidências recentes comprova que a pequena margem no prazo de entrega, o baixo retorno, a pressão para corte de custos (que levam a mais horas de trabalho, a cortes na manutenção etc.) e o pagamento eventual têm comprometido a SST, com efeitos mais pronunciados entre os motoristas localizados na base da cadeia de subcontratações ou da cadeia de fornecedores.

que para os empregados e as empresas subcontratadas) e a culpabilidade, relativa. Em razão disso, o projetista ou fabricante serão responsabilizados por qualquer peça da maquinária que é comprovadamente perigosa devido ao seu projeto ou fabricação (no caso do empregador ter feito todos os esforços possíveis para operar a máquina com segurança e de acordo com as especificações do fabricante). De forma similar, o fornecedor pode também ser responsabilizado se a máquina não estiver defeituosa, mas tiver sido entregue sem as adequadas medidas de proteção ou quando a máquina não está de acordo com as exigências legais requeridas pelas regulamentações de segurança da jurisdição.

Além disso, a subcontratação das atividades não remove as obrigações civis legais de uma organização para manter um sistema de trabalho seguro. Os empregadores têm o dever de proteger não somente os empregados em suas instalações, mas "outros", como os funcionários de empreiteiras, os autônomos subcontratados por eles, os visitantes dos locais de trabalho e os clientes. Inclusive, na maior parte das 
jurisdições da Austrália e da Inglaterra, os deveres dos empregadores para com "outros" estendem-se para além do local de trabalho dos empregadores (JOHNSTONE, 1999). Essas obrigações valem para cada trabalhador individualmente. Isso significa, por exemplo, que se houver uma modificação no sistema de trabalho, a saúde e a segurança de um trabalhador não podem ser comprometidas, mesmo se outros trabalhadores se beneficiarem suficientemente, levando à melhora clara para sua saúde e segurança. Outras obrigações exigem que os empregadores realizem avaliações de riscos e consultem trabalhadores ou seus representantes quando, no processo de trabalho, mudanças que possam afetar a SST são propostas.

Essas obrigações legais de amplo escopo relacionadas com as linhas de responsabilidade horizontais e verticais parecem fornecer a base de uma abordagem integrada para assegurar o cumprimento da regulamentação pela maioria ou, se não, por todas as partes envolvidas numa cadeia de fornecedores. Em resumo, as obrigações legais estabelecem uma cadeia de responsabilidades.

${ }^{7}$ Call centers.

${ }^{8}$ Host employers. fornecedores fora de seu escopo) e havia poucas tentativas das agências de fiscalização em SST de rastrear as cadeias de fornecedores ou de tratar com redes complexas de múltiplas camadas de empresas subcontratadas. Em anos recentes, tem havido mais esforço para se abordar esses aspectos com campanhas orientadas, mas o movimento tem sido fragmentado, parcial e reativo - mantendo-se atrasado em relação às mudanças nas estruturas corporativas e nos diversos arranjos de trabalho.

Segundo, enquanto tem havido crescente atividade de fiscalização para demonstrar as obrigações legais devidas pelos múltiplos detentores de responsabilidades (tais como os empreiteiros principais e subempreiteiros ou agências de contratação de temporários e "tomadores de serviços" ${ }^{8}$ ), o efeito de dissuasão ou do aprendizado dessa fiscalização parece limitado devido ao elevado número de pequenas empresas e considerável rotatividade da mão-de-obra. Ademais, não obstante a legislação, há evidências de uma confusão persistente e de transferência de culpa entre os envolvidos, algo agravado por tentativas abertas ou veladas de ofuscar obrigações legais através de redes de modalidades contratuais, manipulação das modalidades legais de vínculo empregatício (quem é empregado ou autônomo e quem é o empregador) e re-engenharia coorporativa (para tirar vantagem do véu corporativo, o que também torna a identificação dos principais tomadores de decisão mais difícil). Visitas aos locais de trabalho com inspetores de SST têm indicado que tentativas de abordar os detentores de responsabilidades de alto-nível numa cadeia de fornecedores são freqüentemente complexas, difíceis e muito demoradas e enfrentam alta probabilidade de que as decisões serão contestadas. Mesmo ignorando as barreiras jurisdicionais, aqueles que se encontram no topo das cadeias - inquestionavelmente os principais beneficiários - tendem a argumentar que eles não têm controle sobre os que se encontram bem abaixo na cadeia, mesmo onde as prescrições, que eles, com êxito, impuseram com relação à qualidade do produto, aos prazos de entrega etc., os contradigam.

Finalmente, por uma variedade de razões logísticas e outras, é mais difícil, para as inspetorias já sobrecarregadas, proteger trabalhadores contingentes, tais como temporários e trabalhadores domiciliares, porque a força de trabalho é provisória e volátil, móvel e, como acontece com os tra- 
balhadores domiciliares, difícil de localizar e muito mais de inspecionar (JOHNSTONE et al., 2001; QUINLAN, 2004; JOHNSTONE et al., 2005). O desafio para as agências tem sido exacerbado pelo crescente uso de imigrantes (inclusive de imigrantes ilegais) e de trabalhadores temporários estrangeiros ou nativos (estudantes, turistas- mochileiros e "trabalhadores terceirizados de empresas prestadoras de serviço" ${ }^{\text {) }}$ em trabalhos contingentes (inclusive aqueles associados com complexas cadeias de fornecedores na produção de alimentos, de construção, de manufatura e de transporte, na Europa, na América do Norte e na Australásia) (GUTHRIE \& QUINLAN, 2005).

\section{Tentativas recentes de regulamentação de cadeias de fornecedores}

Na Grã-Bretanha e na Austrália, os problemas com o cumprimento das regulamentações relacionadas com as cadeias de fornecedores em certo número de indústrias (como construção, transporte rodoviário, colheita e produção de vestuário) estimularam novas formas de intervenção regulamentadora. Essas iniciativas incluem mecanismos para identificar as responsabilidades legais nas diversas camadas até o topo das cadeias de fornecedores e dispositivos de rastreamento de contratos e processos de fiscalização para se contrapor aos contratos comerciais evasivos, associados com as grandes cadeias de fornecedores. Em certo número de casos (mais notadamente nas facções para confecção de vestuário, mas também com motoristas proprietários e empreiteiros de serviços florestais), isso também acarretou novos sistemas regulamentadores que integram a legislação do trabalho (SST, salários, horas e assim por diante) e o crescente envolvimento da indústria, de sindicatos e da comunidade na fiscalização. Em diversas jurisdições australianas, as obrigações legais ligadas às cadeias de fornecedores foram introduzidas com relação aos casos de homicídios industriais culposos e na legislação voltada à compensação aos trabalhadores.

Na Grã-Bretanha, as regulamentações na área de Projeto e Gestão da Construção ${ }^{10}$ de 1994 impuseram um conjunto de obrigações sobre os clientes de construções, incluindo responsabilidades relacionadas com a nomeação de um supervisor de planejamento e de um empreiteiro principal, que devem ser razoavelmente competentes, e de obrigações ligadas a informações relevantes acerca da SST e a adequados recursos para a proteção da saúde e da segurança dos trabalhadores. Embora vistas como benéficas, as regulamentações não atenderam as expectativas e uma emenda foi recentemente proposta para aumentar o papel que os clientes devem desempenhar, reconhecendo a substancial influência e controle que eles exercem, na prática, sobre os projetos de construção (HSC, 1994). Além disso, enquanto as regulamentações ligadas ao projeto e à gestão da construção esclareceram a distribuição de responsabilidades entre as várias partes envolvidas no planejamento e na execução de projetos de construção, a Comissão Britânica de Saúde e Segurança não apoiou nenhum movimento para estender a lei que regula as contratações nessas cadeias para outras indústrias, argumentando que isso já estava incluído na "Regulamentação da Gestão em Saúde e Segurança no Trabalho" de 1999. Parece que há alguns problemas com essa reivindicação. Mais recentemente, o governo britânico reagiu ao afogamento de 19 mergulhadores chineses, que eram catadores de conchas de moluscos, e a outros abusos, lançando uma coordenada campanha de fiscalização, integrada por muitas agências de governo, chamada "Operação Gangmaster ${ }^{11}$ ”, e apoiando o desenvolvimento de um "Código de Práticas para empreiteiros de mão-de-obra para a produção e comercialização de produtos agrícolas frescos" envolvendo todos os atores da cadeia de fornecedores (TLWG, 2004). Um projeto de lei proposto por um parlamentar individualmente ${ }^{12}$ sobre a matéria - "Lei de (Licenciamento) do Gangmaster" ${ }^{13}$ - foi promulgado pelo parlamento.

No sistema federal da Austrália, a legislação referente à SST é atualmente responsabilidade primária do Estado/Território. Iniciativas recentes na Austrália incluem cláusulas na "Lei sobre Homicídios Culposos na Indústria” do território da capital australiana para as cadeias de fornecedores e revisões na legislação sobre compensação aos trabalhadores em Nova Gales do Sul ${ }^{14}$. Outras duas iniciativas também merecem atenção.

Primeiro, a introdução de legislação regulamentando as formas de subcontratação na indústria de vestuário em Nova Gales do Sul - Lei das Relações Industriais de 2001
${ }^{9}$ Guestworkers.

${ }^{10}$ CDM Regulations 1994: Construction, Design and Management Regulations (Great Britain).

${ }^{11}$ Gangmaster significa agenciador de trabalhadores.

${ }^{12} \mathrm{O}$ que é fato digno de nota, pois se trata de um Private members Bill, que é um projeto de lei apresentado ao parlamento por um membro individualmente e não pelo governo ou pelo partido de oposição. Este membro do parlamento pode também não ser filiado a nenhum partido político. Na Austrália e no Reino Unido, projetos de lei propostos por parlamentares individualmente não são freqüientes e dificilmente tornam-se leis. Quando isso acontece é porque os partidos políticos decidiram apoiar a proposta ou porque permitiram que seus membros utilizassem o "voto de consciência", isto é, permitiram a eles votar de acordo com a sua posição individual, em vez de votar seguindo a orientação do partido.

${ }^{13}$ The Gangmasters (Licensing) Act, 2004.

${ }^{14}$ New South Wales (NSW). 
${ }^{15}$ Muitas vestimentas de marcas famosas são produzidas em fábricas de fundo de quintal ou por trabalhadores em situação precária. A intenção deste sistema é obrigar os detentores das "marcas de roupas famosas" a usar práticas éticas de produção.
(Negociações Comerciais Éticas na Indústria da Confecção) - e subseqüentemente de um código obrigatório de práticas (o Esquema de Responsabilidade Expandida para Negociações Comerciais Éticas na Indústria da Confecção) para assegurar que os trabalhadores subcontratados tenham direitos legais, relacionados com salários, horas e outras condições de trabalho, equivalentes aos trabalhadores empregados nas fábricas, bem como a proteção das leis de SST e os direitos relacionados à compensação aos trabalhadores (NOSSAR et al., 2004). A legislação de Nova Gales do Sul e o código obrigatório têm sido usados como modelos para leis em outros estados e territórios (tais como o território da capital australiana).

O sistema regulamentador, denominado "por trás da marca"15, proibe os varejistas de estabelecerem um acordo com um fornecedor sem que ele tenha se certificado de que este fornecedor ou empreiteiro, ou empreiteiros, de quem ele compra os serviços se utiliza(m) de trabalhadores subcontratados/terceirizados para executar o trabalho e, se assim for, este empreiteiro deve fornecer informações desses trabalhadores, incluindo os nomes e endereços. $\mathrm{O}$ código ou regulamento, além disso, exige uma garantia do fornecedor de que estes trabalhadores subcontratados não recebam “condições menos favoráveis do que aquelas prescritas nos instrumentos industriais pertinentes" (ou seja, semelhante àquelas prescritas em acordo coletivo de trabalho que cobre os trabalhadores internos das fábricas). Uma violação dessa garantia constituiria motivação para interromper o acordo. Os varejistas também são obrigados a dirigir-se por escrito ao Sindicato dos Trabalhadores da Indústria Têxtil, de Confecção e de Calçados da Austrália ou ao Diretor Geral do Conselho de Negociações Comerciais Éticas da Indústria da Confecção. O papel designado ao sindicato reflete o sentimento de que, enquanto muitos trabalhadores subcontratados não forem associados, ele pode exercer função crítica, auxiliando os inspetores do governo a assegurar que as novas exigências sejam, de fato, implementadas.

Um segundo desenvolvimento digno de nota foi a introdução de uma regulamentação retificando a Lei de Saúde e Segurança no Trabalho de Nova Gales do Sul, do ano de 2000, sobre a fadiga de motoristas de caminhão (Emenda de 2005 à Lei Saúde e Segurança no Trabalho de Nova Gales do Sul - Fadiga dos Caminhões de Longa Distância) (NEW SOUTH WALES, 2005). Essa regulamentação requer que os empregadores do setor de transporte rodoviário por caminhões (ou transportadores de cargas) avaliem e tomem medidas para controlar os riscos relacionados com a fadiga dos motoristas de longos trajetos que eles empregam, incluindo a preparação de planos para aliviar a fadiga dos condutores. Grandes transportadores de cargas, consignadores e consignatários também devem preparar planos individuais contra a fadiga dos motoristas para os condutores autônomos que eles contratam. Esses planos devem detalhar a programação das tarefas a serem realizadas, dos itinerários e dos horários das viagens que levam em consideração os tempos necessários para executar as tarefas com segurança, os tempos realmente empregados para realizar tarefas, os períodos de descanso requeridos para fazer face tanto à fadiga imediata quanto à acumulada e as práticas de gerenciamento, incluindo os métodos para avaliar a adaptabilidade dos motoristas; os sistemas de relato para notificação de perigos, incidentes e acidentes e sistemas de monitoramento da saúde e da segurança dos motoristas; o ambiente de trabalho e o conforto das acomodações; treinamento e informação acerca da fadiga que são fornecidos aos trabalhadores; programação de carga e descarga, práticas e sistemas, incluindo as práticas e sistemas para seqüência em filas; e acidentes ou falhas mecânicas. O mais importante é que os regulamentos obrigam os consignadores e os consignatários de frete a realmente monitorarem o cumprimento efetivo das obrigações legais dos transportadores sob a regulamentação, proibindo-os de estabelecer contratos com eles a não ser que eles os satisfaçam com razoáveis bases, assegurando que o planejamento temporal de entregas é razoável para a viagem (incluindo os tempos de carregamento, de descarga e de permanência em filas) e que cada motorista (seja ele empregado ou autônomo) que transporte carga sob o contrato de frete esteja coberto por um plano de gerenciamento da fadiga do motorista.

Uma profunda divisão entre os governos estaduais e territoriais dominados pelo Partido Trabalhista e um governo federal neoliberal significou que as iniciativas adotadas localmente pelos anteriores receberam pouco apoio desse último. O governo federal realmente concordou em fazer dos trabalhadores subcontratados da indústria de vestuário uma exceção para 
seu retorno aos regulamentos trabalhistas mínimos dentro das novas leis de relações industriais, mas uma recente investigação federal junto a empreiteiros independentes recomendou que eles fossem colocados "em quarentena", mesmo considerando as proteções legislativas diminuídas proporcionadas aos empregados regulares. Nem o governo federal, nem suas agências procuraram generalizar as obrigações legais re-

\section{Considerações finais}

Evidências disponíveis indicam que o crescimento de grandes cadeias de fornecedores, nacionais e internacionais, pode solapar as regulamentações em SST existentes e apresentar um profundo desafio para os regulamentadores. Elas, ademais, sugerem que a ação legislativa precisa ser empreendida para abordar esse desafio. As iniciativas legislativas relatadas neste trabalho parecem oferecer um caminho potencial para avançarmos positivamente, porque elas têm como alvo os tomadores de decisão nas cadeias de fornecedores e algumas contêm mecanismos de rastreamento contratual e de procedimentos especiais de fiscalização planejados para se contrapor ao ofuscamento ou à evasão de responsabilidades.

Para serem eficazes, as regulamentações precisarão ser rigorosamente impostas e fiscalizadas e é, ainda, muito cedo para se avaliar a experiência adquirida a esse lativas às cadeias de fornecedores, mesmo nas indústrias nacionais, como a de transporte rodoviário de longa distância, exceto numa maneira fortemente simbólica que ignorou a pressão dos clientes e os custos de frete não-econômicos resultantes da intensa concorrência e do uso de cadeias de subcontratações para explorar pequenas firmas e motoristas autônomos.

respeito. Se elas forem bem-sucedidas, essas iniciativas alterarão a configuração das atividades empresariais, bem como as relações nos locais de trabalho e as condições de SST nas indústrias que elas cobrem. Mais ainda, as leis poderão servir como um modelo genérico para regulamentar as cadeias de fornecedores (RAWLING, 2006). Por outro lado, sua aplicação em maior escala claramente requererá algum nível de coordenação intergovernamental para abordar o crescente fenômeno comum das cadeias de fornecedores atravessarem as fronteiras jurisdicionais internas e internacionais (NOSSAR, 2006). Mais fundamentalmente, talvez, a aplicação mais ampla também requererá superar consideráveis barreiras políticas numa era marcada pela pré-eminência das leis comerciais sobre as leis de proteção social e as tendências desregulamentadoras de parte de muitos governos.

\section{Agradecimentos}

Os autores agradecem a José Marçal Jackson e à Flávia Coelho Rocha pela tradução do texto original em inglês ao português e à Thaís Helena de Carvalho Barreira pela revisão técnica.

\section{Referências}

BELZER, M. Sweatshops on wheels: winners and losers in trucking deregulation. Oxford: Oxford University Press, 2000.

CHRISTOPHER, M. Logistics and supply chain management. $3^{\text {rd }}$ ed. Edinburgh Gate: Prentice Hall, 2005. p. 4-6.

GUTHRIE, R.; QUINLAN, M. The occupational health and safety rights and workers compensation entitlements of illegal immigrants: an emerging challenge.
Pol. Practice in Safety Health, v. 3, n. 2, p. 69-89, 2005.

HSC. Health and Safety Commission. Consultative Document on the Revision of the Construction Design and Management Regulations (CDM). Construction, Health, Safety and Welfare (CHSW), 1994.

JOHNSTONE, R. Paradigm crossed? The statutory occupational health and safety obligations of the business undertaking. 
Aust. J. Lab. Law, v. 12, n. 2, p. 73-112, 1999.

JOHNSTONE, R.; QUINLAN, M.; MAYHEW, C. Outsourcing risk? The regulation of OHS where contractors are employed. Comp. Lab. Law Policy J., v. 22, n. 2-3, p. 351-393, 2001.

JOHNSTONE, R.; QUINLAN, M.; WALTERS, D. Statutory OHS workplace arrangements for the modern labour market. J. Ind. Rel., v. 47, n. 1 , p. 93-116, 2005.

LOUIE, A. et al. Refining measures of employment arrangements and precariousness: empirically-derived categories in a sample of working australians. Relations Industrielles, v. 61, n. 3, p. 465-489, 2006.

MAYHEW, C.; QUINLAN, M. The effects of outsourcing on OHS: a comparative study of factory-based and outworkers in the garment industry. Int. J. Health Services, v. 29, n. 1, p. 83-107, 1999.

Economic pressure, multi-tiered subcontracting and occupational health and safety in Australian long-haul trucking. Emp. Rel., v. 28, n. 3, p. 212-229, 2006.

NOSSAR, I. The scope for effective cross-jurisdictional regulation of commercial contractual arrangements beyond the traditional employment relationship. In: ARUP, C.; GAHAN, P.; MITCHELL, R. (Eds.). Labour law and labour market regulation. Sydney: Federation Press, 2006. p. 202-210.

NOSSAR, I.; JOHNSTONE, R.; QUINLAN, M. Regulating supply-chains to address the occupational health and safety problems associated with precarious employment: the case of home-based clothing workers in Australia. Aust. J. Lab. Law, v. 17, p. 1-24, 2004.
NEW SOUTH WALES. Occupational health and safety amendment (long distance truck driver fatigue) Regulation. 2004.

PLEHWE, D. European trucking: health and safety versus competitiveness? In: TRUCK DRIVER OCCUPATIONAL SAFETY AND HEALTH CONFERENCE, 2003, Detroit (Paper to event).

QUINLAN, M. Flexible work and organisational arrangements: regulatory problems and responses. In: BLUFF, L.; GUNNINGHAM, N.; JOHNSTONE R. (Eds.). OHS regulation in the $21^{\text {st }}$ century. Sydney: Federation Press, 2004. p. 120145.

QUINLAN, M.; BOHLE, P.; MAYHEW, C. The global expansion of precarious employment, work disorganisation and occupational health: a review of recent research. Int. J. Health Services, v. 31, n. 2, p. 335-414, 2001a.

. The global expansion of precarious employment, work disorganisation and occupational health: placing the debate in a comparative historical context. Int. J. Health Services, v. 31, n. 3, p. 507-536, 2001b.

RAWLING, M. A generic model of regulating supply chain outsourcing. In: ARUP, C.; GAHAN, P.; MITCHELL, R. (Eds.). Labour law and labour market regulation. Sydney: Federation Press, 2006. p. 520-530.

TLWG. Temporary Labour Working Group. Code of practice for labour providers to agriculture and the fresh produce trade. Nottingham, 2004.

WRIGHT, C; LUND, J. "Under the clock": trade union responses to computerised control in US and Australian grocery warehousing. New Tech. Work Emp., v. 13, n. 1, p. 3-15, 1998. 